\title{
A DINÂMICA NATURAL DA PRAINHA E DO SEU ENTORNO, MARECHAL DEODORO-AL: UMA ANÁLISE GEOMORFOLÓGICA E SOCIOAMBIENTAL ${ }^{1}$
}

\author{
Jeilson Lima Vieira ${ }^{2}$ \\ Jovesi de Almeida Costa ${ }^{3}$
}

\section{Resumo}

Este trabalho tem como objetivo estudar a dinâmica decorrente dos fatores naturais no local denominado Prainha no município de Marechal Deodoro, Estado de Alagoas. Com a ocupação na zona costeira de Alagoas, as atividades em áreas irregulares vêm ocorrendo de forma espontânea e desordenada, o que tem levado à ocupação de ambientes com risco de inundação e erosão. O estudo mostra que a Prainha e seu entorno é de origem recente e que sua formação foi provocada por sedimentos vindos do continente assim como do oceano, trazidos, principalmente, pelas correntes longitudinais. Os fatores como correntes, ventos, marés e, provavelmente, as mudanças atmosféricas intensificaram sua dinâmica, ocasionado grandes mudanças no ambiente. As atividades desenvolvidas na localidade são o turismo e o lazer implantados de forma espontânea sem nenhum planejamento. Em 2006 a ação marinha, destruiu a Prainha e as estruturas construídas no local para exploração do turismo e para a recreação, mostrando que a ocupação permanente dessa área é muito arriscada.

Palavras-chave: Dinâmica, fatores naturais, geomorfologia, ocupação, turismo.

\section{Abstract}

This work examines the natural dynamics of a beach place called Prainha, municipality of Marechal Deodoro, Alagoas State, in the North-East of Brazil. With urban development in the Alagoas's coastal zone there have occurred spontaneous and unplanned activities. Data provide evidence that the Prainha and its surroundings are geologically recent. They are formed both by continental and marine sediments, these being deposited by longitudinal currents. Factors like currents, winds, tides and possibly atmospheric changes have intensified local natural dynamics, which has led to major changes to the local

\footnotetext{
${ }^{1}$ Monografia apresentada para a obtenção do título de Especialista em Ciências Ambientais.

${ }^{2}$ Licenciado, Bacharel em Geografia e Especialista em Ciências Ambientais pelo Instituto de Geografia, Desenvolvimento e Meio Ambiente da Universidade Federal de Alagoas (Ufal). E-mail: jeilsonlimavieira@gmail.com

${ }^{3}$ Mestre em Geomorfologia e professora da Pós-Graduação Lato Sensu do Instituto de Geografia, Desenvolvimento e Meio Ambiente da Ufal.
} 
environment. Local activities include leisure and tourism, which have taken place without any type of planning. In 2006, the Prainha was significantly changed by the sea dynamics. Leisure and tourism infrastructure was destroyed which suggests that a permanent occupation of the area involves a risk dimension.

Key-words: Dynamics, natural factors, geomorphology, occupation, tourism.

\section{Introdução}

A análise e interpretação das feições morfológicas, suas características, os fatores que as dinamizam e a compreensão e a implicação que essas formas exercem sobre as atividades humanas, tem sido um dos principais objetivos dos estudos geomorfológicos.

Penteado (1978) explica que a análise e explicação da paisagem terrestre e a compreensão de sua organização têm sido a preocupação primordial de profissionais ligados às Ciências da Terra, principalmente a dos Geógrafos.

O litoral alagoano vem passando por transformações importantes no tocante à sua dinâmica espacial, tanto por fatores naturais como antrópicos. Estes por meio de ocupações, na maioria das vezes, irregulares em áreas de risco com grande dinamismo natural.

Este estudo tem como objetivo analisar as alterações no meio físico de uma área do litoral do município de Marechal Deodoro (Estado de Alagoas) explorada pelo o turismo e lazer, denominada Prainha. Visa também descrever a geomorfologia da área e do seu entorno.

O conteúdo de que se compõe este estudo (afora introdução, resultados, discussões e conclusão) foi estruturado em três partes: a primeira tem como tema $\mathrm{O}$ ambiente da Prainha e as implicações espaciais através da sua dinâmica natural, a segunda identifica a geologia e geomorfologia da Prainha e do seu entorno e a terceira enfoca a utilização do espaço da Prainha para o turismo e lazer.

Apesar da intensa ocupação de áreas frágeis, não propícias a determinadas atividades (o que vem ocorrendo em todo litoral alagoano) e de se considerar o dinamismo natural de áreas com risco iminente e os impactos resultantes dessas ocupações, os estudos sobre o tema não são frequentes. É importante que mais estudos sejam desenvolvidos a fim de que se entenda e se busquem soluções para o uso sustentável dessas áreas de grande dinamismo natural. $\mathrm{O}$ conhecimento gerado pode servir de referência para o planejamento e a gestão de atividades no litoral alagoano, principalmente aquelas relacionadas ao turismo e lazer.

Utilizou-se como material e método na realização deste estudo recursos tecnológicos como os softwares Terra View 3.3.0 e gvSIG que são livres e usados para mapeamentos, geoprocessamento e confecção de mapas. As referências foram organizadas consultando-se 
literaturas que explicam a formação da Terra. No levantamento de campo, procurou-se ir além da mera observação da paisagem, já que a geomorfologia requer olhos aguçados do pesquisador para a interpretação das feições. Foram coletadas informações em órgãos ambientais municipais e estaduais. Para completar a base de dados do estudo, realizou-se levantamento fotográfico com o objetivo de registrar as características físicas da Prainha e do seu entorno.

Complementando as pesquisas de campo, foram entrevistadas pessoas que fazem parte da organização e vivência do espaço pesquisado: comerciantes, moradores, empregados de bares e restaurantes, turistas, barqueiros e pescadores. Já em relação ao recurso metodológico, buscou-se também a percepção que esses atores sociais têm sobre o problema em foco.

\section{O ambiente da Prainha e as implicações espaciais através da sua dinâmica natural}

O ambiente natural de qualquer área da superfície terrestre é resultado da ação de processos que nela atuam durante um longo período de tempo.

Em qualquer ponto da superfície interagem forças de origem diferentes: algumas emanam do interior da crosta, são as chamadas forças internas ou endógenas; outras provêm do exterior, são chamadas forças externas ou agentes externos ou exógenos. Isso ocorre porque é na superfície do planeta que se encontram as três camadas que compõe a Terra: a camada sólida, a líquida e a gasosa. O ponto de encontro dessas três camadas é chamado por alguns teóricos de "Epiderme da Terra" ou "Estrato Geográfico". É nesse ponto de contato que surgem as formas de relevo sobre as quais a vida vegetal e animal se desenvolveu.

Nas áreas costeiras, a interação entre os processos provenientes dessa tensão é mais visível, porque nela os processos astronômicos, meteorológicos e oceanográficos atuam sobre os sedimentos que dão origem às formas características do litoral: terraços marinhos, cordões arenosos ou litorâneos, restingas, dunas e recifes. A ação desses processos, quando violentos, pode destruir formas e invadir o continente.

Em Alagoas, a ocupação da orla costeira intensificou-se nos últimos 20 anos, e tem trazido sérios problemas relacionados à erosão costeira, saneamento, poluição, destruição dos manguezais e outros danos que poderiam ser evitados se houvesse um planejamento efetivo e a contribuição dos órgãos responsáveis.

A Prainha, objeto deste estudo e que está localizada próximo à Boca da Barra que liga o Canal de Fora do Complexo Estuarino Lagunar Mundaú-Manguaba com o oceano (Figura 1), é um desses locais da costa alagoana que teve sua ocupação rápida e sem nenhum planejamento com a finalidade de atender ao turismo e lazer. 


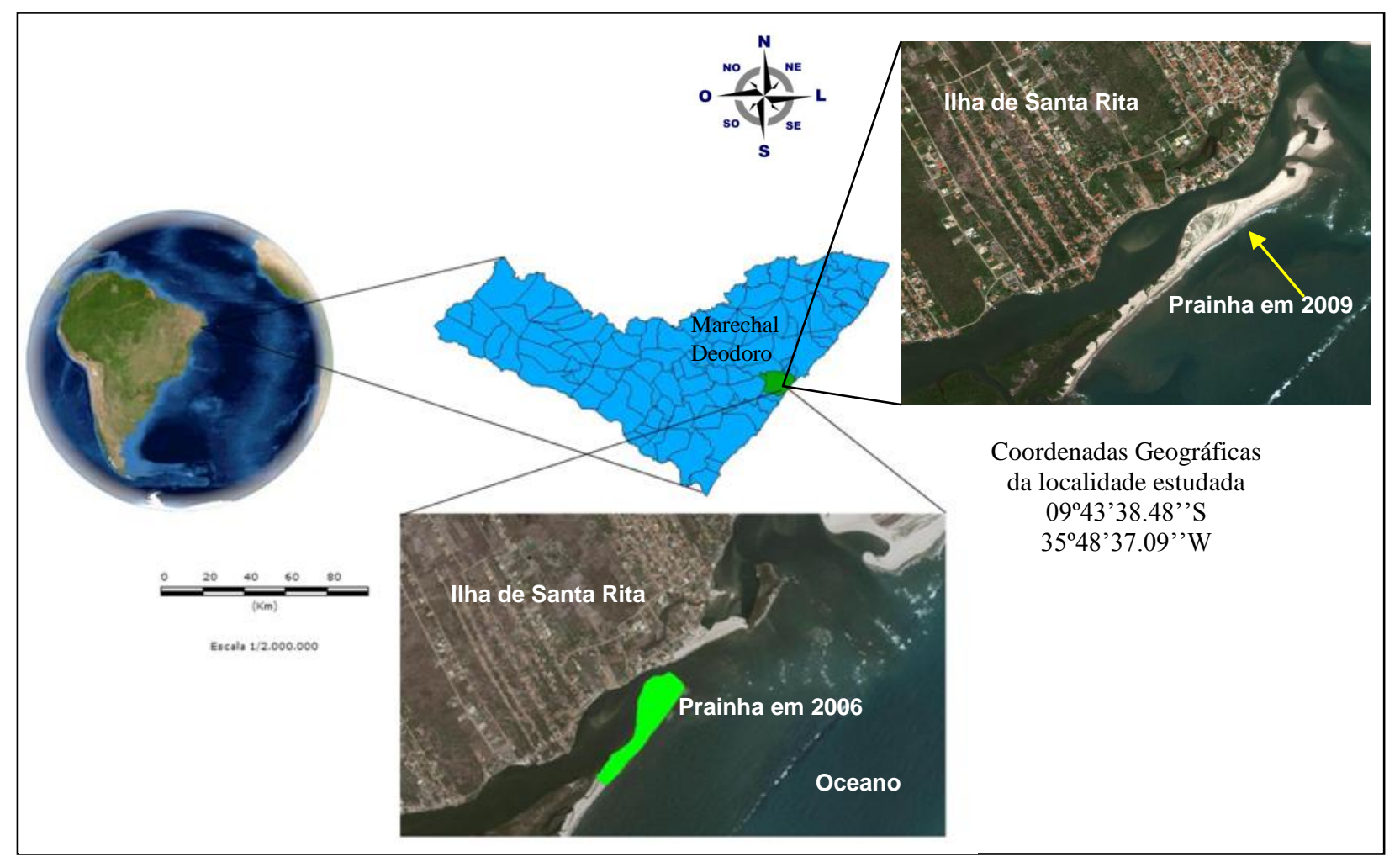

Figura 1. Mapa de localização da Prainha.

Fonte: Embrapa, IBGE e Google Earth.

A área do Complexo Estuarino Lagunar Mundaú-Manguaba (CELMM) onde está localizada a Prainha provavelmente começou a se construída no Plioceno, quando teve início a deposição de sedimentos terciários da formação Barreiras, há mais ou menos 5 milhões de anos A. P. (Antes do Presente). Esses sedimentos, segundo Andrade e Bigarella (1964) apud Santos (2004), foram carreados para o sopé das encostas cristalinas sob clima semi-árido com chuvas esporádicas violentas, que provocavam enxurradas e depositavam os sedimentos sob formas de leques aluviais, os quais se estenderam até a plataforma continental, já que o nível do mar estaria cerca de $100 \mathrm{~m}$ abaixo do atual.

Nesse período, a separação dos continentes americano e africano, iniciada no Cretáceo, já havia atingido a longitude atual da costa nordestina, tendo a área em estudo passado pela fase de golfo, encontrando-se na fase de mar aberto. Com as variações do nível do mar os sedimentos foram retrabalhados modificando a localidade.

As flutuações climáticas, variações do nível do mar e as mudanças na dinâmica costeira foram as causas principais da evolução das paisagens, principalmente no ambiente costeiro. O CELMM é, portanto, resultado dos processos de transgressão, regressão marinhas e de movimentos tectônicos no fim do terciário até o Quaternário. 
Há cerca de 120.000 anos A. P., no máximo da penúltima transgressão marinha, uma parte da sedimentação proveniente das dinâmicas anteriores foi retrabalhada, cursos fluviais no interior do continente foram afogados, começando a formar as lagunas. Essas transformações não ocorreram apenas no litoral alagoano, mas no litoral de quase todo Brasil.

Posteriormente, iniciou-se novamente um recuo do mar. As áreas onde os cursos dos rios anteriormente haviam sido afogados pela penúltima transgressão começam a ter característica de lagunas. Com esse recuo, originou-se uma vasta planície formando terraços marinhos pleistocênicos. Conforme Coutinho e Lima (1998), Costa e Ramos (2004), os terraços pleistocênicos têm uma altitude de $8 \mathrm{~m}$ a $10 \mathrm{~m}$, atualmente correspondem às áreas do centro de Maceió, na Ilha de Santa Rita (CELMM) e nas proximidades da praia do Francês em Marechal Deodoro. Esse ambiente foi construído logo após a penúltima transgressão marinha há aproximadamente 120.000 anos A. P.

Por volta de 7.000 e 5.500 anos A. P., já no Holoceno, o nível do mar voltou a elevarse, atingindo entre $4 \mathrm{~m}$ e $5 \mathrm{~m}$ acima do atual. Durante essa transgressão, os terraços marinhos pleistocênicos foram retrabalhados, e dessa dinâmica resultaram as barras. Na desembocadura das antigas rias Mundaú e Manguaba, com um novo recuo do nível do mar as barras retêm as águas dos estuários afogados, concretizando finalmente a construção dos corpos lagunares, que hoje são as lagunas Mundaú e Manguaba.

Com todas essas características em sua formação, a Prainha é considerada um ambiente sensível, podendo sofrer variações no seu entorno e em todo seu ambiente. Portanto ocupações permanentes nessas localidades têm que ter um planejamento efetivo para que não haja riscos para quem a ocupa.

Segundo Vieira (2007), em 2006 houve uma grande ressaca na área estudada que destruiu completamente a Prainha, causando danos significativos em estruturas antrópicas implantadas no local e nas proximidades (Figuras 2). Após três anos esse ambiente começou a ser reconstruído.

Correntes, marés, ventos e principalmente a aceleração gravitacional influenciam diretamente na intensa dinâmica da localidade. As intensificações desses fenômenos atmosféricos, oceânicos, astronômicos e continentais deram contribuições significativas na modificação geomorfológica do ambiente estudado.

Atualmente a Prainha está sendo retrabalhada com a deposição de novos sedimentos. Isso se deve aos fatores naturais, que atuam na área, e já se observa a mesma praticamente refeita. Com isso, sua ocupação com estruturas construídas para o turismo e lazer já é novamente uma realidade (Figura 3 ). 


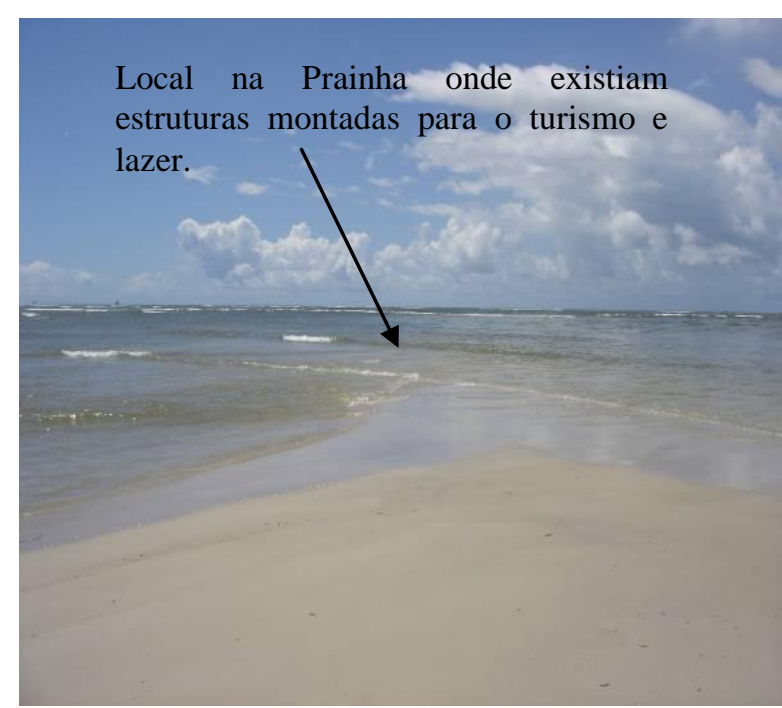

Figura 2. Prainha destruída pela ressaca ocorrida em 2006.

Fonte: Labtur/Igdema/Ufal, 22/3/2007.

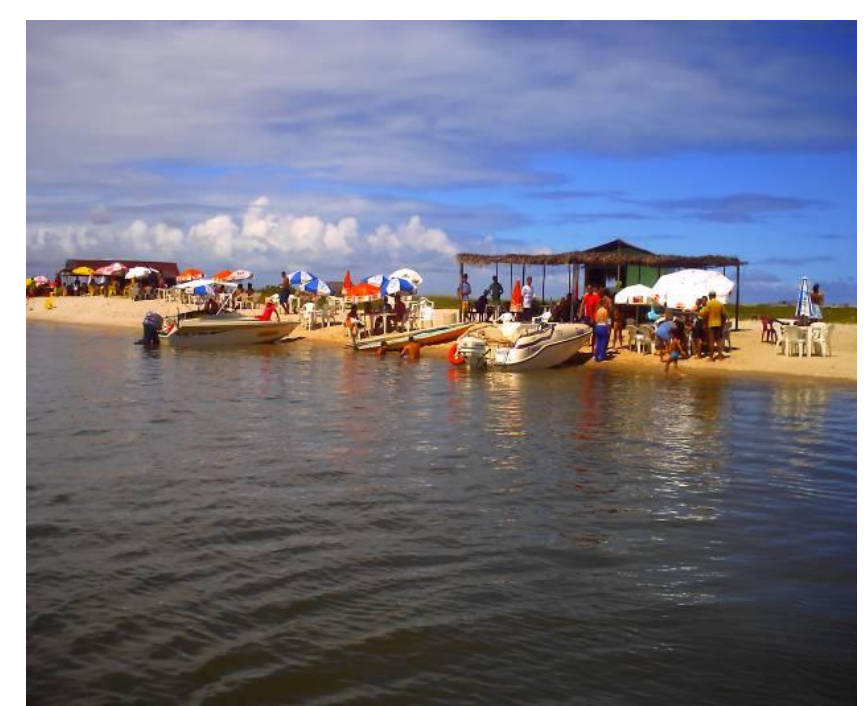

Figura 3. Prainha praticamente reconstruída, e com estruturas antrópicas erguidas para o turismo e lazer 3 anos após a ressaca.

Fonte: próprio autor em, 4/9/2009.

A formação geomorfológica da área da Prainha e do seu entorno resulta da ação de fatores descritos neste estudo, os quais têm grande capacidade de construção e destruição do ambiente com muita rapidez. Em ambientes assim, a ocupação espacial sem um planejamento adequado pode implicar em sérias consequências sociais, econômicas e ambientais.

\section{Geologia e geomorfologia da Prainha e do seu entorno}

A formação geológica, em boa parte dos casos, guarda registro da evolução das paisagens. A descrição geológica permite definir e caracterizar alguns processos naturais que acompanham a evolução dos ambientes naturais (BLOOM 1988, p. 95).

A geologia da costa alagoana, onde está situada a Prainha, é basicamente sedimentar, com rochas que vão do Cretáceo ao Quaternário, mas precisamente até o Holoceno, sendo encontradas as primeiras em sub superfície, e representadas, conforme Santos (2004), pelos grupos Igreja Nova, com as formações Batinga e Aracaré, grupo Perucaba, de origem fluviolagunar, através das formações Candeeiro, Bananeira e Serraria. Posteriormente, foram depositados os sedimentos clásticos do grupo Coruripe, representados pelas formações Barra de Itiúba, Penedo, Coqueiro Seco, Porção, Ponta Verde e Maceió.

Sobrepostos a esses três grupos, estão os grupos Sergipe, com formações Riachuelo e Cotinguiba, e o grupo Piaçabuçu composto pelas formações Calumbi, Mosqueiro e Marituba.

Subsequente às formações acima citadas foram depositados os sedimentos da formação Barreiras, que ocorrem em superfície no início do Quaternário. Atualmente, tais 
sedimentos podem ser observados no entorno do corpo lagunar e no litoral, os quais são muito utilizados na construção civil. Todos esses grupos fazem parte de uma das grandes unidades estruturais do globo, a Bacia Sedimentar. No Estado da localidade estudada é denominada de Bacia Sedimentar Alagoas (SANTOS, 1998, p. 39).

Atualmente, o processo de deposição e erosão na Bacia Sedimentar Alagoas nas proximidades da Prainha advém da variação do nível do mar e de outros agentes, provocando acúmulo e retiradas de sedimentos modificando por completo a paisagem.

Os estudos geomorfológicos são importantes para entender a dinâmica ocorrida em ambientes como o da Prainha. A Geomorfologia como ciência que estuda o relevo, isto é, as formas da superfície terrestre, além de descrevê-las, ainda tem como objetivo analisar a gênese dessas formas, considerando a complexidade física, química e biológica de suas interrelações, individualizadas nas paisagens (JATOBÁ; LINS, 2008 p. 11-12).

Jatobá e Lins (2008) esclarecem que entre os diversos componentes das paisagens naturais, o relevo terrestre é aquele que exerce uma das mais expressivas influências sobre as várias atividades humanas.

Nos dias atuais, o conhecimento das formas da litosfera torna-se imprescindível em qualquer estudo sobre a ocupação do ambiente, uma vez que a implantação de atividades antrópicas em determinadas áreas depende, na maioria das vezes, de estudos que têm como objetivo atender tanto à viabilidade do empreendimento como descrever os impactos provocados na natureza por essas atividades. Assim, o estudo geomorfológico é de grande importância para a implantação de atividades, como turismo, agricultura, geração de energia, criação de rodovias e habitações.

A geomorfologia do litoral alagoano compreende duas unidades: os tabuleiros costeiros que são oriundos do terciário, e a planície marinha formada no Quaternário. A Prainha e parte do seu entorno está espacilaizada na planície marinha, nessas unidades encontram-se diferentes feições, oriundas de depósitos que se estenderam do fim do Terciário até o Quaternário. Fazem parte da paisagem: recifes, praias, terraços lagunares, cordões litorâneos, terraços flúvio-marinhos, várzea fluvial, terraços coluvio-aluvionáres, rampas de colúvio, falésias fósseis, vales fluviais decapitados, encostas de vales fluviais e ainda formas resultantes da ação antrópica, representadas pelo aterro na cabeceira da ponte, que liga a restinga de Maceió à Ilha de Santa Rita, localizada sobre o Canal de Fora (Figura 4). O ambiente em que a Prainha está inserida começou a ser formado devido a uma grande dinâmica paleoclimática, com sucessões de clima semi-árido, frio e seco no final do Terciário estendendo-se pelo Quaternário (GOES, 1979, p. 225). 


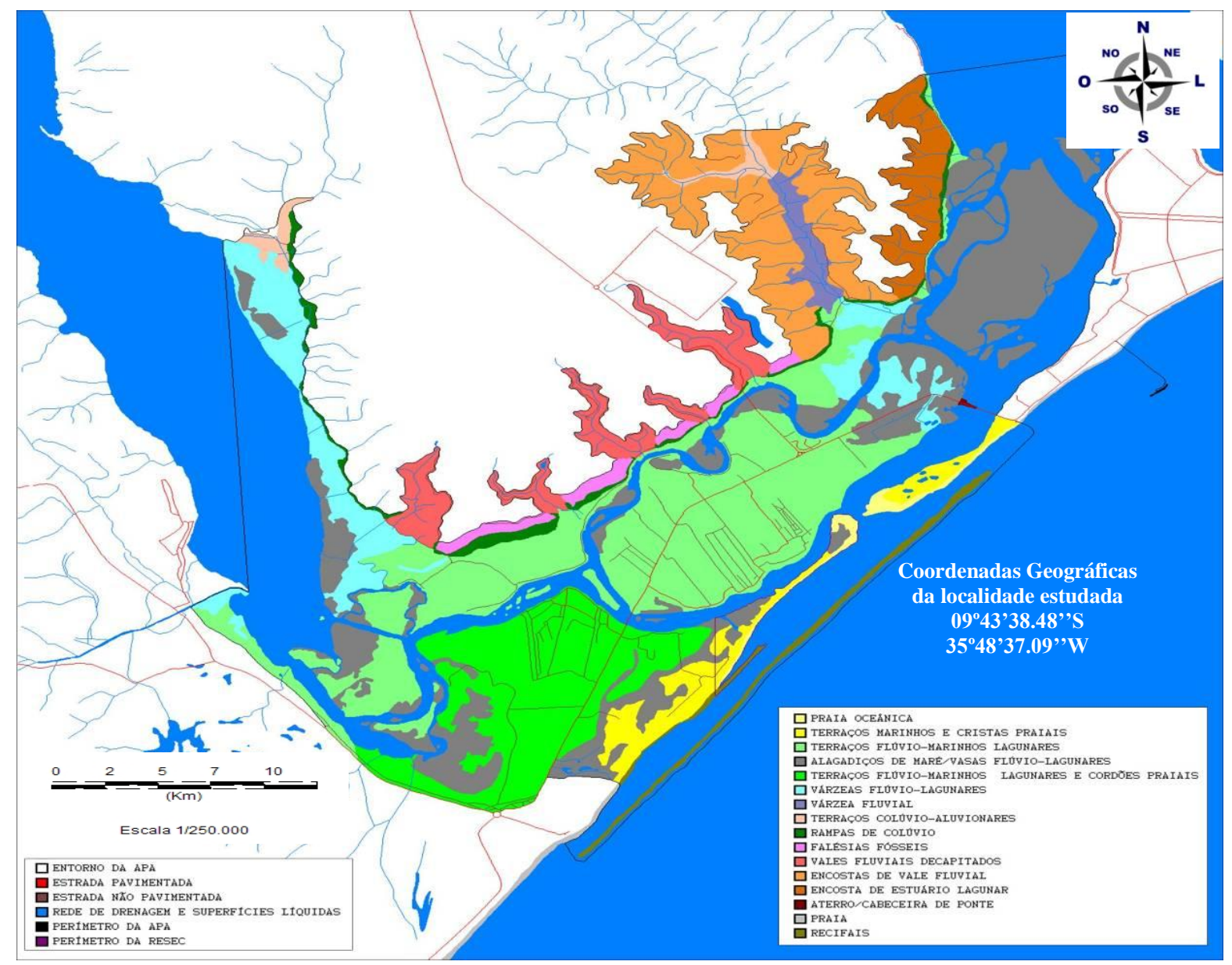

Coordenadas geográficas da localidade 0943'38.48', S $35^{\circ} 48^{\prime} 37.09^{\prime \prime} \mathrm{W}$

Figura 4. Mapa geomorfológico da Prainha e do seu entorno.

Fonte: Plano de Manejo e Gestão Ambiental da Área de Proteção Ambiental (APA) de Santa Rita IMA-Chesf-IPPA, 2003.

A Prainha como "lugar-território" é classificada, geomorfologicamente, por pesquisadores de diversas ciências, basicamente de duas formas: alguns seguem a linha de que a área é um cordão litorâneo, outros que é uma restinga ou a ponta final dela, esclarecendo que é um complemento da restinga do Pontal, bairro da capital alagoana. Segundo Lima (1990), uma boa parte da cidade de Maceió foi construída sobre uma restinga, que se estende do centro de Maceió, mais precisamente da Rua Zacarias de Azevedo, nas imediações da Santa Casa de Misericórdia, até o Pontal da Barra. Nela se desenvolveu parte do centro e dos bairros do Prado e Trapiche da Barra e todo bairro do Pontal da Barra.

Christofoletti (1980) enfatiza que as restingas são de extrema importância e que, em algumas literaturas, são descritas como barreiras ou cordões litorâneos. Lima (1990) define 
restinga como sendo "barragens naturais de sedimentos que se formam e cruzam aberturas de baías, estuários ou 'rias' transformando-os em lagunas". Esclarece, ainda, que algumas lagunas, mais precisamente as que se prendem à base de uma falésia, dependem da construção de restingas ou de terraços eustáticos para completar a sua formação.

No litoral de Maceió existe uma autêntica restinga, uma vez que para que isso ocorra deve haver uma barreira arenosa (restinga de Maceió) ligada a uma estrutura mais resistente (terraço estrutural do centro de Maceió), em cuja base passava o canal que liga a laguna com o mar (antigo canal que passava pelo parque Rodolfo Lins e rua Dias Cabral) com suas pontas arenosas (LIMA, 1990, p. 128).

Assim, observa-se que a restinga de Maceió corresponde ao "polier", barreira arenosa que atravessa a boca do rio Mundaú, enquanto a área do Francês-Massagueira-Taperaguá é o “mousoir”, área entulhada, que se prolonga através de um terraço holocênico em direção à restinga de Maceió. No prolongamento desse terraço, encontra-se a Prainha, que tapou e desviou o estuário do rio Paraíba do Meio (Figura 5).

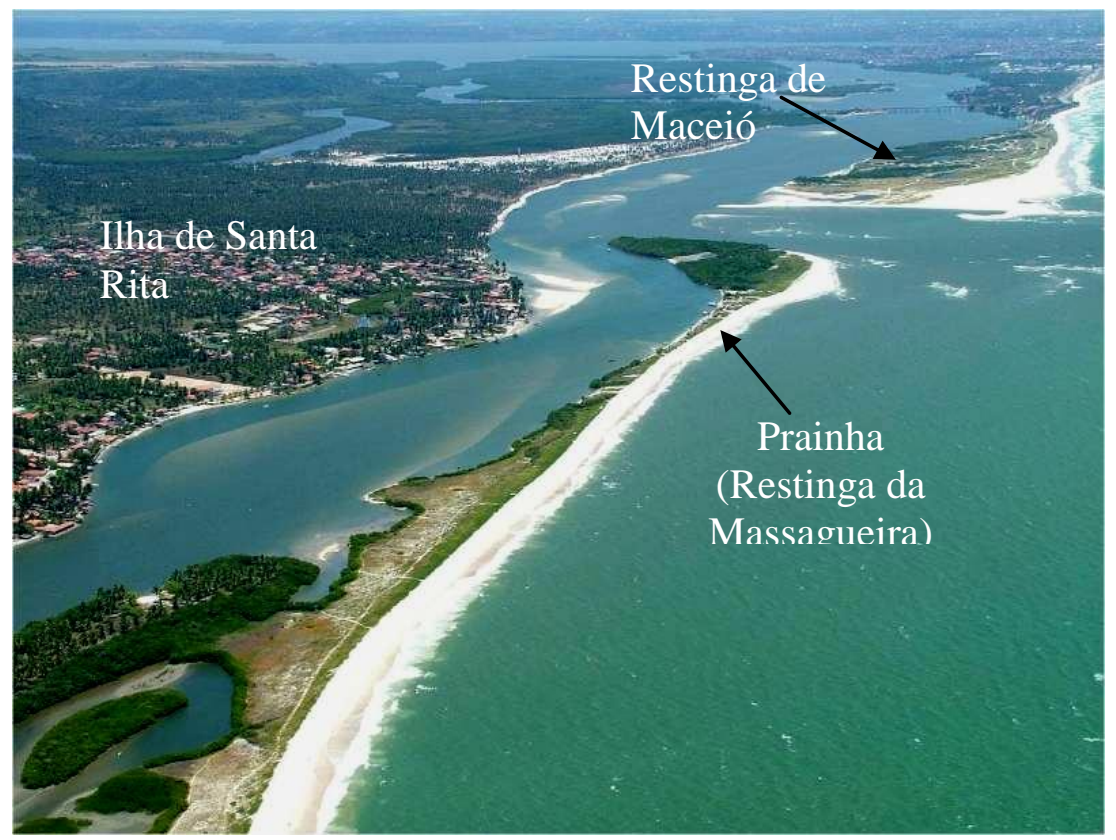

Figura 5. Prainha no centro da figura, prolongamento do terraço holocênico, que tapou e desviou o estuário do rio Paraíba do Meio.

Fonte: Erimar Bayma.

A Prainha é o prolongamento de um terraço de origem marinha holocênico, que se ligou à área entulhada da Massagueira barrando e desviando as águas do rio Paraíba do Meio, podendo ser chamada de restinga da Massagueira, tendo praticamente na sua formação as mesmas características da restinga de Maceió. Essa feição foi construída com influência dos ventos, marés e principalmente pelas correntes longitudinais. Segundo Lamego (1946) apud 
Christofoletti (1980), essas correntes atacam saliências litorâneas, transportando os sedimentos, tapando e desviando estuários de rios e lagunas.

\section{A utilização do espaço da Prainha para o turismo e lazer}

No entorno da capital alagoana, inúmeros ambientes naturais, dominados pela presença do mar, atraem turistas nacionais e internacionais além de residentes locais que a eles se dirigem em busca de recreação. É o caso da Prainha, que, antes de sua destruição em 2006, atraía muitas pessoas durante todo ano.

Com sua reconstrução por fatores naturais, a Prainha está retomando as atividades de turismo e lazer (Figura 6). As empresas que trabalham com turismo incluem como grande atrativo, passeio de barcos, catamarans e outras embarcações. Nessa opção há o chamado "passeio das nove ilhas", (através da laguna Mundaú), saindo do Pontal da Barra e finalizando na Prainha.

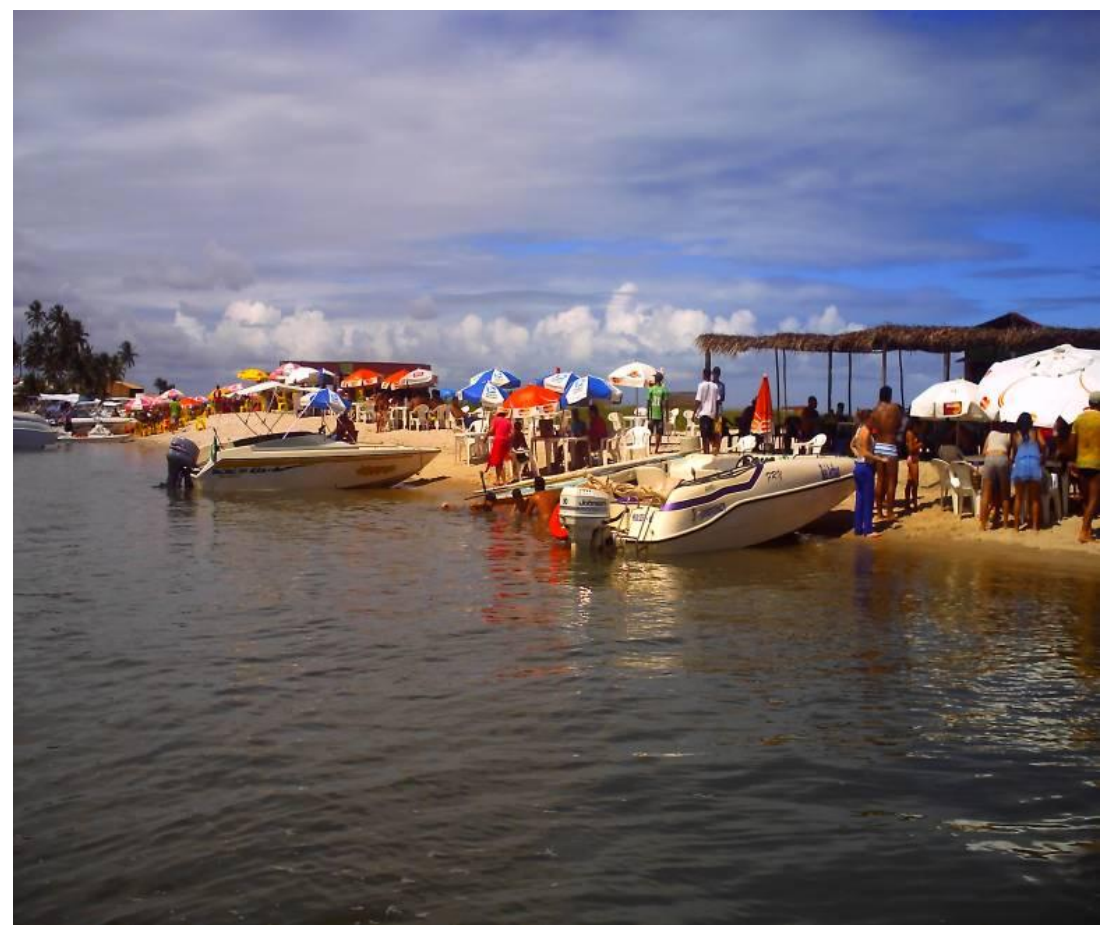

Figura 6. Atividades de turismo e lazer retomadas depois da reconstrução da Prainha,

Fonte: próprio autor em, 4/10/2009.

As atividades de turismo e lazer têm importante papel socioeconômico, principalmente na geração de emprego e renda. Segundo alguns proprietários de bares da Prainha, várias famílias dependem dessa atividade para sobreviver. A organização dessas atividades é imprescindível, pois são muito importantes para a comunidade local. 
A ocupação humana da Prainha, além de ser comprometida pela dinâmica natural, contraria a legislação ambiental que prevê o seu uso só para fins de pesquisa, já que ela está dentro de uma área de proteção integral da Reserva Ecológica Saco da Pedra ${ }^{4}$.

A dinâmica natural na localidade faz com que estruturas construídas irregularmente sobre a linha de praia ou nas suas proximidades se encontrem em condições de risco. A dinâmica rápida do ambiente, desencadeada por fenômenos naturais, coloca em risco o patrimônio material. É necessário que algumas áreas que apresentam risco sejam controladas rigorosamente, a fim de evitar que nelas sejam construídas estruturas permanentes (Figuras 7).

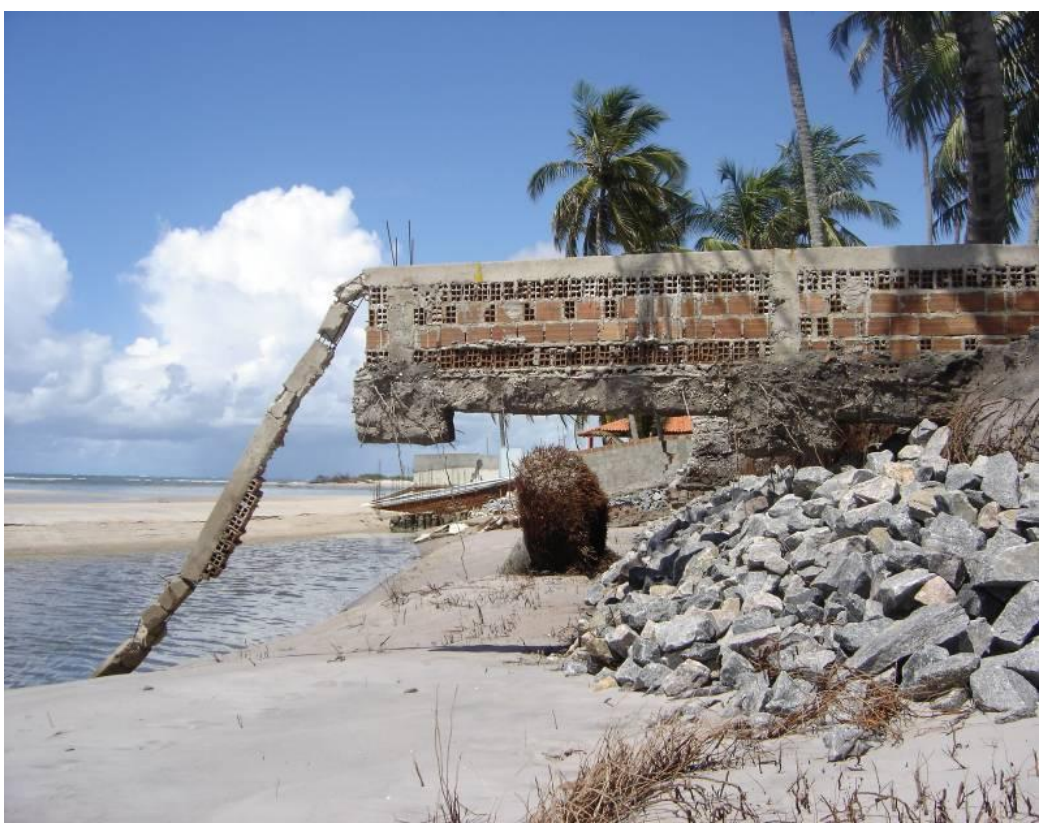

Figura 7. Estruturas para veraneio próximas à Prainha, destruídas com a ressaca ocorrida em 2006.

Fonte: Labtur/Igdema/Ufal, 22/3/2007.

Uma das provas mais convincentes da necessidade de se ordenar a ocupação e o uso de áreas litorâneas foi a destruição da Prainha, juntamente com todas as estruturas físicas erguidas no local e de algumas construções às margens dos canais. A mudança brusca que ocorreu na área, em 2006, causando prejuízos materiais, indica a necessidade de evitar a ocupação permanente de ambientes semelhantes ao longo da linha de costa alagoana.

\footnotetext{
${ }^{4}$ Segundo o Sistema Nacional de Unidades de Conservação da Natureza (SNUC), a categoria Reserva Ecológica foi extinta, sendo implantadas outras categorias de proteção integral como, Reserva Biológica e Estação Ecológica, mas alguns Estados ainda utilizam o termo Reserva Ecológica para classificar essas áreas. É o caso de Alagoas.
} 
A perspectiva do desenvolvimento não pode ser usada como motivo para ocupações sem planejamento, sem responsabilidade. A ocupação e a construção do espaço é condição intrínseca ao ser humano, mas não se devem ultrapassar determinados limites impostos pela natureza.

A Geomorfologia pode prestar uma contribuição significativa nos estudos regionais de exploração espacial, como ressalta a citação a seguir:

\begin{abstract}
A Geomorfologia pode dar uma contribuição significativa, na medida em que procura compreender os processos formadores do relevo bem como a sua dinâmica externa, que pode ser mais ou menos afetada, em virtude do tipo de ocupação a que uma determinada porção do território possa está sendo exposta (GUERRA; MARÇAL, 2006, p.31).
\end{abstract}

Os estudos geomorfológicos podem ser empregados para uma melhor adequação em determinadas áreas, sem que isso implique na inviabilidade de atividades que exploram essas localidades.

\title{
Resultados e discussões
}

A evolução paisagística da Prainha e do seu entorno foi e é causada por fatores naturais, mas a ação antrópica tem atuado de forma desordenada, o que tem contribuído para agravar a situação, já que, com sua ocupação, um acidente natural, como o ocorrido em 2006, traz grandes problemas para a população. Apesar de Chritofoletti (1980) enfatizar que as formas costeiras têm sua dinâmica baseada na interação tectônica, eustática, erosiva e deposicional, deve-se compreender que a ação antrópica com certeza interfere em sua dinâmica, causando danos, às vezes irreversíveis, na paisagem natural.

A Prainha como "espaço-território" teve e tem suas modificações impostas naturalmente. A sua destruição e reconstrução se deram por uma série de fatores naturais, dentre eles: as correntes que carreiam sedimentos, retrabalhando-os e modificando ambientes, ora sedimentando ora erodindo; os ventos que retrabalham os sedimentos e intensificam as ondas e podem provocar aporte e retirada de areias; as marés, que são influenciadas principalmente por fatores gravitacionais, são responsáveis pelas grandes ressacas e subida momentânea do nível eustático; além de mudanças gerais na circulação atmosférica.

A destruição da Prainha e do seu entorno, ocorrida em 2006, e, posteriormente, sua reconstrução em pouco tempo, foi um fato de ordem local, pois não se sabe de atividades 
tectônicas em larga escala nos últimos anos no oceano Atlântico com capacidade de provocar mudanças bruscas na costa do continente sul americano.

A explicação mais provável para a destruição da Prainha é que mudanças bruscas no sistema atmosférico tenham intensificado todos os agentes geomorfológicos culminando com sua destruição. Bloom (1988) explica que alterações no sistema atmosférico podem causar mudanças bruscas na litosfera, graças à intensificação dos processos que atuam na superfície terrestre.

A geomorfologia está descrita, neste artigo, prioritariamente, para se ter uma ideia de que forma deve-se planejar o espaço para melhorar seu ordenamento. Esse estudo como foi visto, apesar de certa complexidade, apresenta feições fáceis de serem identificadas na paisagem, a exemplo de terraços, recifes e falésias.

A Prainha conforme este artigo recebe uma nova classificação como feição geomorfológica; é a parte final da área de terraço do Francês-Massagueira-Taperaguá, que fecha a desembocadura da laguna Manguaba, denominada a partir deste estudo de Restinga da Massagueira.

A área estudada é um local de forte atração turística, por estar localizada entre o Canal de Fora - que interliga as lagunas Mundaú e Manguaba - e o mar, o que lhe empresta beleza natural, principal motivo das visitas de turistas e de habitantes locais, já que sua ocupação não sofreu nenhum planejamento para receber esses visitantes. O lugar como atrativo turístico se deu de forma espontânea.

As entrevistas feitas a moradores, turistas, ocupantes que exploram economicamente a Prainha, pessoas que utilizam para o lazer e autoridades ligadas aos órgãos ambientais e de turismo, resultaram em uma grande preocupação relacionadas às questões ambientais e também ao dinamismo natural da localidade, já que a ocupação não teve nenhum planejamento antes de sua destruição e nem após sua reconstrução natural. Isso significa que, ocorrendo outro desastre natural, pode haver novas perdas econômicas ou até de vidas humanas.

A exploração de espaços faz parte do processo evolutivo do homem, principalmente atividades que possibilitem a apreciação da paisagem como o turismo. A Prainha é um desses espaços, mas o que se vê é a exploração da atividade turística de forma completamente equivocada, sem planejamento e feita aleatoriamente. Barreto (2002) afirma que o turismo feito desordenadamente e sem planejamento prévio, provavelmente, acarretará implicações socioambientais graves. 
A Prainha é um exemplo dessa afirmação. Por causa do grande dinamismo natural, a ressaca ocorrida em 2006 destruiu as estruturas implantadas no local e nas margens dos canais das lagunas. Isso indica que a ocupação permanente da Prainha e em ambientes com essas características é um equívoco grave.

\section{Conclusão}

Com base no presente estudo conclui-se que:

- a área estudada é de grande importância socioeconômica e ambiental;

- a ocupação desordenada e irregular é fator de preocupação, uma vez que causa impactos ambientais negativos;

- em sua ocupação, observa-se franca desobediência à legislação em vigor;

- geomorfologicamente trata-se de uma área de formação recente sujeita a fatores eustático, erosivo e deposicionais;

- a destruição e reconstrução da Prainha por meio da remoção e deposição de sedimentos é natural e rápida;

- a área voltou a ser usada para o turismo e lazer em virtude da reconstrução natural do ambiente. Mais uma vez sem planejamento;

- não há nenhuma interferência do poder público, o que mostra a ausência de políticas públicas para ordenar e planejar a área.

Diante do que foi exposto neste artigo, conclui-se ainda que ocupação do espaço requer acima tudo, o conhecimento físico do ambiente, no qual o planejamento deve vir em seguida. Só assim provavelmente diminuirá o desordenamento urbano e os impactos ambientais.

\section{Referências}

ALAGOAS. Instituto do Meio Ambiente. Estudo de ordenamento das ocupações nas Áreas de Proteção Ambiental. Maceió: Biblioteca do IMA, 2004, 102p.

ANDRADE, G. O. BIGARELLA, J. J. Considerações sobre a estratigrafia dos sedimentos cenozóicos em Pernambuco (Grupo Barreiras). Arquivos do Instituto Ciências da Terra, v. 2, 1964, p. 1-14.

BARRETO, M. Planejamento e organização em turismo. 7. ed.. Campinas: Papirus, 2002. $101 p$. 
BLOOM, A. L. Superfície da Terra. São Paulo: Edgard Blücher, 1988. 174p.

BRASIL. Presidência da República. Casa Civil. Lei n 9.985 , 2000. Subchefia para assuntos jurídicos, Brasília, jul. 2000.

BRASIL. Universidade Federal de Alagoas. Instituto de Geografia, Desenvolvimento e Meio Ambiente. Laboratório de Turismo, Maceió, set. 2007.

BRASIL. Ministério do Planejamento, Orçamento e Gestão. Instituto de Geografia e Estatística. Mapas. Disponível em: <http://ibge.gov.br/mapas_ibge/>. Acesso em: 15 de maio. 2009.

BRASIL. Ministério da Agricultura, Pesca e Abastecimento. Empresa Brasileira de Pesquisa Agropecuária. Geoprocessamento e sensoriamento remoto. Disponível em: <http://www.embrapa.br>. Acesso em 25 de set. de 2009.

CHRISTOFOLETTI, A. Geomorfologia. 2. ed.. São Paulo: Edgard Blücher, 1980. 188p. COSTA, J. A.; RAMOS, V. Á. Organização do Espaço Geográfico do Estado de Alagoas. In: ARAUJO, L. M. (Org.). Geografia: espaço, tempo e planejamento. Maceió: Edufal, 2004, p. 191-205.

COUTINHO, P. N.; LIMA, R. C. A. Modelo evolutivo do Sistema Estuarino Lagunar Mundaú-Manguaba. Revista do Labmar da Ufal, Boletim de Estudos da Ciência do Mar, Maceió, n. 10, p. 139-153, 1995.

GOES, M. H. B.. Ambientes costeiros do Estado de Alagoas. Rio de Janeiro, 1979, 339f. Dissertação (Mestrado em Geografia) Universidade Federal do Rio de Janeiro, 1979.

GOOGLE. Google Earth. Imagem de Satélites. Disponível em: $<$ http//earth.coogle.com/download-earth.html>. Acesso em: 12 de jun. de 2009.

GUERRA, A. J. T.; MARÇAL, M. S. Geomorfologia ambiental. Rio de Janeiro: Bertrand Brasil, 2006. 189p.

JATOBÁ, L.; LINS, R. C. Introdução à geomorfologia. 5. ed.. Recife: Bagaço, 2008. 244p.

LAMEGO, A. R. O homem e a restinga. 2. Ed.. Rio de Janeiro: Serviço Gráfico, 1946. 224p.

LIMA, I. F. Maceió a cidade restinga: contribuição ao estudo geomorfológico do litoral alagoano. Maceió: Edufal, 1990. 255p. 
PENTEADO, M. M. Fundamentos de geomorfologia. 2. ed.. Rio de Janeiro: IBGE, 1978. $154 \mathrm{p}$.

SANTOS, R. C. A. L. Evolução da linha de costa a médio e curto prazo associada ao grau de desenvolvimento urbano e aos aspectos geoambientais na planície costeira de Maceió Alagoas. Recife, 2004, 155f. Tese (Doutorado em Geologia Sedimentar e Ambiental) Universidade Federal de Pernambuco, 2004.

SANTOS, R. C. A. L. Estudo sedimentológico e geoambiental no Sistema Lagunar Mundaú Alagoas. Recife, 1998, 127f. Dissertação (Mestrado em Geologia Sedimentar e Ambiental) Universidade Federal de Pernambuco, 1998.

VIEIRA, J. L. Estudo ambiental da Prainha e do seu entorno com base no uso turístico e no lazer. Maceió, 2007, 51f. Monografia (Graduação em Geografia) Universidade Federal de Alagoas, 2007. 